\title{
Editorial
}

\section{Toward using everybody's intelligence and knowledge}

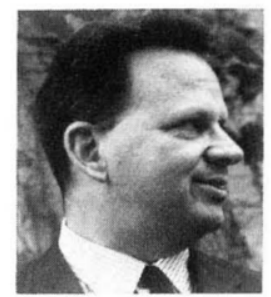

Leonard Uhr was born in Philadelphia, Pennsylvania in 1927. He received his B.A. from Princeton and Ph. D. from University of Michigan in 1957 , in psychology.

He was a Research Scientist at the Mental Health Research Institute and an Associate Professor of Psychology at University of Michigan, leaving in 1965 to become a Professor of Computer Sciences at the University of Wisconsin.

He conducted a number of experiments on the behavioral effects of psychoactive drugs, including tranquilizers, psychic energizers and hallucinogenic agents, publishing two books: "Drugs and Behavior", and "Drugs and Phantasy", as well as a number of papers.

He soon became interested in the potential power of the computer as a tool with which to model intellectual functions, especially perception and learning. He has written computer programs on pattern recognition, scene description, perceptual learning and language learning, using the kinds of processes that human beings seem to use. He has published over 100 papers on various aspects of this research, and also two books: "Pattern Recognition", and "Pattern Recognition, Learning and Thought".

His long-term goal is to develop a program that models the integrated "wholistic" cognitive functions performed by any ordinary human being. For example, the way an infant learns to recognize and pick up to a piece of fruit, or the way an adult learns how to handle a new set of knobs on a new stereo receiver.

These appear to be simple tasks compared to playing world-championshiop chess or proving new mathematical theorems, and any non-impaired human being can handle them. But they are at the heart of human intelligence which we still know so little about. (Modeling of human cognitive functions will inevitably lead to more intelligent computers, since we can then program our understanding into the computer.)

Professor Uhr is also interested in the new large arrays and networks of computers that are now being developed. These are necessary to model the brain, and to effect such highly parallel tasks as perception and recognition, or control of a motor system in real time.

Finally, he has been trying to develop a self-organizing responsive computer network that would draw its users into the system, in a mutual effort to build, add to and improve upon the resources of the system. This is one example of the kind of participant-responsive system discussed in the accompanying editorial.

() North-Holland Publishing Company

Human Systems Management 1 (1980) 201-203
I am pleased to have been asked to write the editorial for this issue of Human Systems Management, and given the chance to be controversial.

I want to suggest an unusual approach to managing, planning and directing for which, I think, the time may be ripe. We are at the threshold of several new technologies that will make the suggested organizational structure possible, and desirable.

In essence, our world is far too complex for any single individual to be 'expert' enough and 'wise' enough to make the needed decisions. Nor should one, or a few, individuals be asked, or feel they have the prerogative, to make decisions for a larger group. On the other hand, almost all of us are reasonably intelligent, and are concerned and quite knowledgeable about a number of things that affect our lives and that we care about.

We now have the tools - in very cheap computers; cable, telephone and other communication links; user-friendly programs and interactive terminals; statistical techniques for gathering, organizing and displaying the import of information; and an understanding of the decision-making process - that would make possible the implementing of informationgathering and decision-making procedures radically different from and, I would argue, potentially more equitable and more productive than those we use today.

The manager, planner, director or governor would, in such a participant-responsive self-organizing structure, serve several vital roles, in encouraging, organizing, and using information and opinions from all participants, and encouraging and implementing good decisions and procedures. Managers could invite and use ideas from others, rather than have to fend them off. The manager's own expertise would be many times augmented by the combined knowledge of the whole group. 
Can any single individual be chosen and trained to manage?

We have come deep into an era of 'trained experts' who (try to) run our businesses, our services, our government, our cities, and even large portions of our lives. In the past it was the king or his lieutenants, or the landowner, who ran things. Today we feel we have made major improvements because it is the welltrained expert, who was admitted by and did well at a good school, giving us every reason to think that she/he is both bright and learned.

But one (reasonably intelligent) person is not really that much brighter than the next. And we don't know enough about choosing people, either when we admit them to school or when we hire and promote them as a function of their (seeming) success to be at all confident in our choices. Most of our problems are far too complex for any single person to handle wisely.

\section{A few examples of participatory, responsive organiza- tions}

Consider some examples that should give you a feeling for the issues involved. Then we can look at some more general principles.

The planners in the City Traffic Department decide where to put traffic lights, 'No Left Turn' signs and little yellow squiggles. They have been taught the basic principles in traffic planning courses, and they did well in their case studies and exams. But they are severely understaffed and very busy, and nobody would expect them to even inspect each possible site, much less return to all the corners with lights, and go to all the corners without lights, to see whether the right corners had been chosen.

Nor would anybody expect them to make an individual study of each corner, to decide whether to use this or that type of timing control, or to decide exactly how to set the timing. For that, they will use their expert knowledge, to choose the type of corner, and the type of light, that the texts say studies showed were best in Buffalo in 1963.

But we are all experts about the traffic lights in our own neighborhoods, and the large number of other little (and big) problems that confront us every day on our way to work and on our daily rounds. We all have the opportunity to use our great knowledge to groan and curse under our breaths, or to write a letter to the newspaper, or to the Traffic Planning Department. An adept Traffic Planning Department may take the time to reply, to explain to us why we are wrong, and to justify, by accumulating a reputation for responsiveness with a lot of replies, more staff to explain things.

A few of us are crackpots, and some of us have poorer judgment than others. But it is hard to believe that the hundreds of people who notice and care about each of the little (and big) things in our cities and our societies do not have more information, and more insight, that might potentially be brought to bear to improve things. than do the 2 or 3 hopelessly overworked planners.

As an overly simple first step, we might start with little Suggestion Boxes under each traffic light; we should read these suggestions, publish their results, ask for comments and more suggestions. We should then act upon what people have suggested. After all, the planner is simply trying to handle things for the benefit of the community.

We can of course improve upon the above procedure. Rather than a Suggestion Box, we can have a phone number, or a form in the newspaper that prompts people to notice what annoys and pleases them, and gives them a simple way to jot these things down and mail them in. A newspaper column that summarized and reported what was on people's minds, and what had actually been done about things, and what evidence there was that this indeed had improved things, would, I think, be read.

Another quick example: Most universities, when they put a new building on the campus, lay out sidewalks as part of the design. On a few campuses, grass is grown and then people walking to and from the building make natural paths that many find useful. After several years, these paths are, if necessary, cast in concrete.

\section{Computer network-based responsive self-organizing groups}

In 5 or 10 years our television sets will contain computer terminals linked by cable to a computer network, and there will be similar terminals on street corners and in drug stores, wherever we find telephones today (indeed the telephones will also serve as terminals to this network). We might then implement systems of the following sort:

Anybody interested would be asked to report on 
whatever aspects of city (or country) life she/he liked, or was bothered by. For example, restaurants (and also stores, scenic drives, bike paths, plumbers, movies, traffic lights, politicians - indeed anything anybody wanted to comment about) would be assessed. Everyone would be encouraged to input such information into the computer network, Electronic Mail. Bulletins (daily, weekly, or whatever the consensus of assessors suggested was most desired) would give highlights of the results, and people could request more detail on issues that especially interested them.

Each individual must make some effort to participate. But if the system gives back useful, pertinent, fresh, responsive information on just those topics the individual has found worth participating in, most people will, I suspect, feel richly rewarded.

One of the manager's major functions in such a system is to arouse and sustain interest. This I suggest is best done by making participants feel that their ideas and efforts are being considered, rather than fended off or ignored. The encouragement by Japanese management of workers to participate and feel involved, along with careful and responsive use of information about productivity, has many elements of such a society.

The government of a shared resource, like a park, or the city buses, or the city, or an automobile factory, would also benefit from the knowledge and thought of its participants and workers.

Institutions that involve their members and implement their choices

This of course sounds, and to some extent indeed is, utopian. But it is an organizational structure that in most aspects is quite similar to structures that have been around for a long time and are widely used, including natural evolution, free enterprise and participatory democracy.

The manager becomes the arbiter who encourages the flow and analysis of information, and implements the decisions the whole group has chosen. And the computer is introduced as the basis for a system that gathers and organizes information from all the members of the community (who are involved and interested). The managers' jobs are to get and use as much of this information as possible.

To a great extent this is a practical philosophy, an attitude toward societies and institutions and how they might best be planned, managed and governed. It tries to use each individual as much as possible, but within controls that keep every individual equal. It is rather like a town hall participatory democracy (which may finally be feasible with computer networks handling things) combined with true free enterprise competition - but between the different alternatives that people as users have been encouraged to suggest, try out and evaluate.

To work, it would need interested, involved participants. But we are beginning to realize how desirable that is.

Leonard UHR 